\title{
EuroQol (EQ-5D-5L) Validity in Assessing the Quality of Life in Adults With Asthma: Cross-Sectional Study
}

Gimena Hernandez ${ }^{1,2,3}$, MD, MPH; Olatz Garin ${ }^{1,3,4}$, MPH, PhD; Alexandra L Dima ${ }^{5}$, PhD; Angels Pont ${ }^{1,3}$, BSc; Marc Martí Pastor ${ }^{1,2,3}$, MD, MPH; Jordi Alonso ${ }^{1,3,4}$, MD, PhD; Eric Van Ganse ${ }^{5,6}$, MD, PhD; Laurent Laforest ${ }^{6}, \mathrm{MD}, \mathrm{PhD}$; Marijn de Bruin ${ }^{7}$, PhD; Karina Mayoral ${ }^{1,2}$, MPH; Vicky Serra-Sutton ${ }^{3,8}$, PhD; Montse Ferrer ${ }^{1,2,3}, \mathrm{MD}, \mathrm{PhD}$; ASTRO-LAB Group

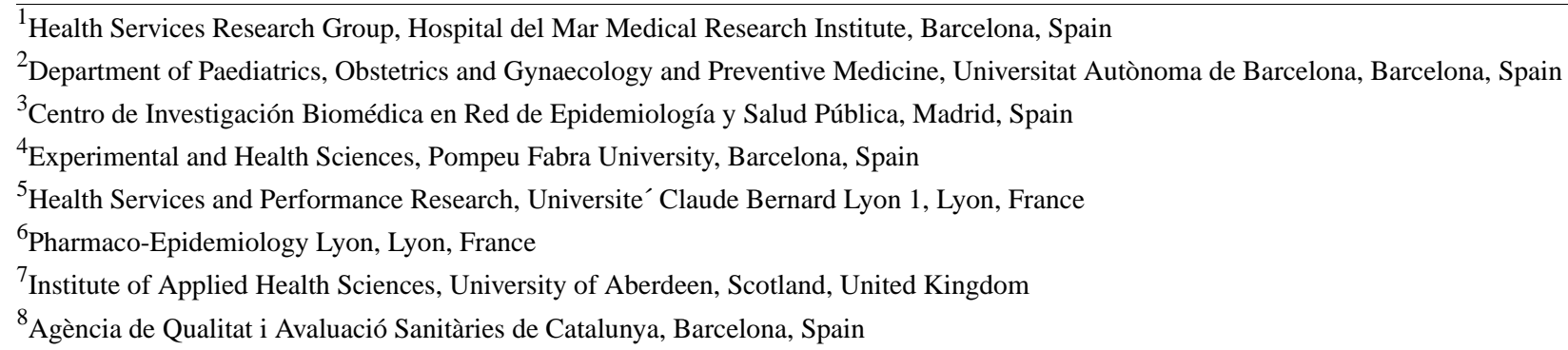

\section{Corresponding Author:}

Montse Ferrer, MD, PhD

Health Services Research Group

Hospital del Mar Medical Research Institute

Dr Aiguader 88

Barcelona, 08003

Spain

Phone: 34933160763

Fax: 34933160797

Email: mferrer@imim.es

\section{Abstract}

Background: The EuroQol-5 Dimension (EQ-5D), developed in 1990, is a most widely used generic tool to measure the health-related quality of life (HRQoL) and considered suitable for patients with asthma. In 2009, the EuroQol Group developed a new EQ-5D version to overcome limitations related to its consistently reported high ceiling effect. To enhance the sensitivity for assessing the HRQoL in further patient populations, the number of responses of EQ-5D was increased from 3 to 5 levels (EQ-5D-5L). Moreover, the availability of well-defined requirements for its Web-based administration allows EQ-5D-5L use to monitor the HRQoL in electronic health (eHealth) programs. No study has evaluated the metric properties of the new EQ-5D-5L in patients with asthma yet.

Objective: This study aims to examine the distribution, construct validity, and reliability of the new EQ-5D-5L questionnaire administered online to adults with asthma.

Methods: We evaluated patients with asthma (age: 18-40 years) from a primary care setting in France and England, who self-completed the EQ-5D-5L questionnaire online. The inclusion criteria were persistent asthma defined as $>6$ months of prescribed inhaled corticosteroids and long-acting beta-agonists or inhaled corticosteroids alone during the 12 months prior to inclusion. The EQ-5D index was obtained by applying the English preference value set for the new EQ-5D-5L and the French $3 \mathrm{~L}-5 \mathrm{~L}$ crosswalk value set. Both value sets produced single preference-based indices ranging from 1 (best health state) to negative values (health states valued as worse than death), where $0=$ death, allowing the calculation of quality-adjusted life years. Responses to dimensions and index distribution, including ceiling and floor effects, were examined. The construct validity was assessed by comparing the means of known groups by analyses of variance and calculation of effect sizes.

Results: Of 312 patients answering the baseline Web-based survey, 290 completed the EQ-5D-5L (93\%). The floor effect was null, and the ceiling effect was 26.5\% (74/279). The mean EQ-5D-5L index was 0.88 (SD 0.14) with the English value set and 0.83 (SD 0.19) with the French 3L-5L crosswalk value set. In both indices, large effect sizes were observed for known groups defined by the Asthma Control Questionnaire $(1.06$ and 1.04, $P<.001)$. Differences between extreme groups defined by chronic 
conditions ( $P=.002$ and $P=.003$ for the English value set and French 3L-5L crosswalk value set, respectively), short-acting beta-agonists (SABAs) canisters in the last 12 months $(P=.02$ and $P=.03)$, or SABA use during the previous 4 weeks $(P=.03$ and $P=.01)$ were of moderate magnitude with effect sizes around 0.5 .

Conclusions: The new EQ-5D-5L questionnaire has an acceptable ceiling effect, a good construct validity based on the discriminant ability for distinguishing among health-related known groups, and high reliability, supporting its adequacy for assessing the HRQoL in patients with asthma. EQ-5D-5L completion by most Web-based respondents supports the feasibility of this administration form.

(J Med Internet Res 2019;21(1):e10178) doi: 10.2196/10178

\section{KEYWORDS}

asthma; EQ-5D-5L; EuroQol; health-related quality of life; Web-based survey; validity; patient-reported outcome measures

\section{Introduction}

The impact of asthma on the patients' health has been traditionally assessed by either clinical markers or functional tests [1]. Patient-reported outcome measures, such as symptom control or health-related quality of life (HRQoL), have shown to be useful for clinical management, understanding disease impact on the patients' functional status and well-being, and cost-effectiveness analyses [2]. Hence, international guidelines for asthma diagnosis and treatment have emphasized that treatment goals should include the improvement of the patients' HRQoL [3].

In asthma, disease-specific HRQoL measures have been more widely used than generic ones, as they could be more sensitive. Adding generic HRQoL domains important to patients with asthma has been proposed [4] because asthma-specific HRQoL instruments measure similar contents to those covered by asthma control questionnaires [5,6] such as symptoms and activity limitations. Generic HRQoL instruments are broad measures that can be applied in patients with various conditions and the general population. The EuroQol-5 Dimensions (EQ-5D), developed in 1990 by the EuroQol Group, is one of the most widely used generic tools owing to its low respondent burden, good psychometric properties, and econometric development [7-9]. In addition, the availability of well-defined requirements for its Web-based administration by multiple devices, such as personal computer, tablet, or smartphones, makes this instrument adequate for monitoring the HRQoL in eHealth programs [10].

The EQ-5D was considered a suitable generic measure in a systematic review [11] of patient-reported outcome measures for patients with asthma. This health status measure allows the calculation of quality-adjusted life years (QALYs) when society preferences are applied and cost-utility analysis in economic evaluations [12-14]. However, to the best of our knowledge, only 3 studies have evaluated its psychometric properties in patients with asthma [15-17]. Garratt et al [16] showed a moderate EQ-5D association with asthma-specific HRQoL instruments and external variables such as smoking status and education level. Oga et al [15] and McTaggart-Cowan et al [17] reported a high ceiling effect $(59 \%$ and $50 \%$ of the sample with the maximum score, respectively) questioning the usefulness of the EQ-5D in asthmatic patients. In fact, limitations related to the high ceiling effect have also been consistently reported for the EQ-5D in other chronic conditions such as chronic obstructive pulmonary disease [18], osteoarthritis [18], diabetes [19], and coronary heart disease [20].

The traditional EQ-5D descriptive system, composed of 5 dimensions with 3 levels of severity, defines 243 distinct health states resulting from all the possible combinations (ie, $3^{5}$ ); this is a low number compared with other generic preference-based instruments such as the Health Utilities Index [21] or the SF-6D [22] with 972,000 and 18,000 possible combinations, respectively. To improve its sensitivity, the EuroQol Group developed a new EQ-5D version, by increasing the number of responses from 3 to 5 levels, known as EQ-5D-5L, with 3125 health states $\left(\mathrm{ie}, 5^{5}\right.$ ) [23].

The new EQ-5D-5L has already been tested in some disease-specific samples, such as patients with cancer [24,25] and with hepatitis [26], showing a better discrimination capability and lower ceiling effects than the traditional 3-level version (11\% vs $17 \%$ [24], 9.7\% vs $16.8 \%$ [25], and $21.6 \%$ vs $38.3 \%$ [26]). However, to date, no study has evaluated metric properties of the new 5-level EQ-5D in patients with asthma. Hence, this study aims to examine the distribution, construct validity, and reliability of the new EQ-5D-5L administered online to adults with asthma.

\section{Methods}

\section{Setting and Study Population}

In this study, we analyzed baseline data of adults (age: 18-40 years) enrolled in the ASTRO-LAB cohort who completed the EQ-5D-5L questionnaire. The ASTRO-LAB project is a prospective longitudinal study of asthmatic patients designed to provide new evidence regarding the safety of long-acting beta-agonists (LABAs) in routine primary care in France and the United Kingdom. Details of the study are described elsewhere [27].

The inclusion criteria were as follows: persistent asthma and age $<40$ years. Patients were considered to have persistent asthma when they had $>6$ months of prescribed treatment with inhaled corticosteroids (ICs) and LABAs or ICs alone during the 12 months prior to inclusion. Persistent asthma requires controller therapy on a regular basis, whereas intermittent asthma can be treated with rescue medication as needed. The ASTRO-LAB persistent asthma definition was based on a minimal prescription duration level of antiasthmatic drugs because this method is considered less biased than the 
practitioner's classification of asthma, and it is frequently used in database studies [28]. The ASTRO-LAB project's age limit was chosen to minimize the recruitment of patients with other comorbid conditions frequent at older ages, most importantly chronic obstructive pulmonary disease, often overlapped and difficult to exclude without specific tests.

The exclusion criteria were as follows: chronic oral corticosteroid use ( $\geq 15$ consecutive days 3 months before inclusion), history of omalizumab therapy, and any other concomitant chronic respiratory disease (chronic obstructive pulmonary disease, cystic fibrosis, pulmonary fibrosis, bronchiectasis, or tuberculosis). Owing to ASTRO-LAB's main focus being LABAs safety, the abovementioned criteria based on the administration of other medications aimed at avoiding confounding with their adverse effects, implying that most patients with severe persistent asthma were excluded.

The ASTRO-LAB study has been approved by the Ethics and Regulatory Boards in France and the United Kingdom and was conducted in accordance with the Declaration of the World Medical Association. In France, approval was obtained from CCTIRS (Comité consultatif sur le traitement de l'information en matière de recherche dans le domaine dela santé) on November 21, 2012 (Dossier $\mathrm{N}^{\circ} 12702$ ), and the authorization from Commission Nationale d'Informatique et Liberté was obtained in May 17, 2013 (DR-2013-264). In the United Kingdom, according to the UK Research Governance Framework, the study was submitted to The West London Research Ethics Committee (REC), and the final approval was obtained on April 15, 2013 (REC Reference 12/LO/20139). Following the UK regulatory process, the ASTRO-LAB consortium submitted the protocol to the National Institute for Health Research Clinical Research Network (NIHR CRN) to launch the review by Primary Care Trust local sites. The first local approval was granted by the West London Primary Care Consortium on May 22, 2013. Informed consent was obtained from all participants prior to inclusion.

\section{Measurement Instruments}

Clinical data were extracted from medical records, and patient-reported information was obtained by the following 2 administration modes: patient-completed Web-based survey and telephone interviews with patients performed by trained interviewers. The EQ-5D-5L was only administered in the Web-based survey.

\section{Clinical Data}

Information on age, gender, body mass index, comorbidity, and treatment prescribed was obtained; in France, general practitioners completed a Web-based survey at patient inclusion, while in the United Kingdom, this information was directly extracted from medical records. The history of 4 associated pathologies (allergic rhinitis, nasal polyps, anxiety or depression, and gastroesophageal reflux), was registered and transformed into a count variable. The total number of short-acting beta-agonist (SABA) canisters prescribed in the 12 months prior to inclusion was transformed into a variable of 3 categories- -0 , $1-4$, and $\geq 5$ canisters.

\section{Patient-Completed Web-Based Survey}

Patients received instructions during the recruitment contact to self-complete a Web-based survey, which included the EQ-5D-5L to measure the HRQoL and sociodemographic data, such as their highest level of education and current work situation, among others.

The EQ-5D-5L is a brief, multiattribute, generic, health status measure composed of 5 questions with Likert response options (descriptive system) and a visual analog scale (EQ-VAS). The latter asks patients to rate their own health from 0 to 100 (the worst and best imaginable health, respectively). The descriptive system covers 5 dimensions of health (mobility, self-care, usual activities, pain or discomfort, and anxiety or depression) with 5 levels of severity in each dimension (no problems, slight problems, moderate problems, severe problems, and unable to perform or extreme problems).

Preference value sets used to obtain the index of the EQ-5D-5L were the 3L-5L crosswalk from the French 3L version [29], and the new EQ-5D-5L value set from England [30]. In both cases, single preference-based indices were produced ranging from 1 (the best health state) to negative values (health states valued as worse than death), where $0=$ death. The minimal important difference for the EQ-5D index was estimated as 0.07 [31].

\section{Telephone Interviews}

The telephonic interviews were computer-assisted to standardize the process. Trained interviewers administered questions to patients about their asthma control and treatment use, among others. Asthma control is defined as the extent to which the manifestations of asthma can be observed in a patient, or have been reduced or removed by treatment [32,33]; it reflects the suitability of the asthma treatment.

The Asthma Control Questionnaire (ACQ) is composed of 7 items - the top scoring 5 symptoms, $\mathrm{FEV}_{1} \%$ predicted, and daily rescue bronchodilator use. A shorter version called ACQ-symptoms only [34] was developed to use when it is not feasible to collect data about the last 2 items, as in ASTRO-LAB. It assesses the frequency of the 5 asthma symptoms during the previous week on a 7-point Likert scale $(0=$ no impairment, $6=$ maximum impairment $)$. The overall score, calculated as the mean of item responses, ranges from 0 to 6 . A score $<0.75$ was defined as well-controlled asthma; 0.75-1.5 as intermediate control; and $>1.5$ as not well-controlled asthma [35]. The results generated by the short versions have shown to be very similar to those of the complete ACQ, as well as its measurement properties (reliability, responsiveness, internal consistency, construct validity, and interpretability) [34].

The following question was asked to patients with SABA therapy prescription: "How often have you usually taken your 'reliever medication' (brand name) in the past 4 weeks? Every day; almost every day; once or twice every week; less than once a week; or I don't know."

\section{Analytic Strategy}

Sample characteristics were described by calculating percentages, or mean (SD) values, according to the variable type (detailed in tables and figures). To examine the nonresponse 
bias, subjects who completed the Web-based survey were compared with those who had not completed this survey by a $t$ test and chi-square test.

We calculated the percentages of responses to each EQ-5D-5L dimension. To examine the distribution of the EQ-5D index, we calculated statistics of central tendency, dispersion, asymmetry, and tail extremity, as well as the proportion and 95\% CI of the individuals in the best possible (ceiling) and the worst possible (floor) health states [36]. To assess the reliability based on the internal consistency, the Cronbach alpha coefficient was estimated.

The construct validity examines whether the instrument adequately assesses the concept that it intends to measure [37], in this case the HRQoL. The strategy to evaluate the construct validity based on known groups consists of testing the ability of the instrument to discriminate among groups previously hypothesized as differing in the concept measured. The following variables were chosen to test the instrument's capacity to discriminate, as differences have been consistently shown in the HRQoL among groups defined by them [1,15,38,39]— the number of chronic conditions (as an indicator of general health), number of SABA canisters prescribed in the previous year, frequency of SABA inhaler use during the previous 4 weeks, and ACQ scores (as 3 indicators of asthma control). We hypothesized that asthma patients with worse general health or less asthma control report worse HRQoL.

To evaluate the discriminative capacity of the EQ-5D index and EQ-VAS among the known groups mentioned above, mean scores were compared using one-way analysis of variance and the Tukey studentized range (honestly significant difference) test for post-hoc comparisons; alpha was set at.05. To assess the magnitude of the differences Cohen effect sizes were calculated. General guidelines define an effect size of 0.2 as small, 0.5 as moderate, and 0.8 as large [40]. All analyses were conducted using the statistical package SPSS (IBM SPSS Statistics for Windows, Version 23.0, IBM Corp)

\section{Results}

\section{Study Sample}

Of 581 subjects with asthma aged 18-40 years composing the ASTRO-LAB cohort, 312 filled in the baseline Web-based survey (Web-based participation rate, 53.7\%), but 22 of these did not complete the EQ-5D-5L (questionnaire nonresponse rate, $7.0 \%$ ). Of 290 who fulfilled the EQ-5D-5L, 11 were excluded because they had missing data on all the variables selected to define known groups; hence, 279 patients were finally included in this analysis. Table 1 shows patients' baseline characteristics, comparing the included subjects with excluded ones (mainly because of not responding to the Web-based survey). Most of the included subjects were from France and had been treated with fixed-dose combinations of LABA and IC. More than half of them had completed a bachelor degree
(66.9\%, 184/275), and 72.6\% (201/277) were employed in their usual jobs. These 2 variables were only available for patients included in the analysis, as they were recorded in the Web-based questionnaire. Nonrespondents were younger (aged 29.8 vs 31.0 years, $P=.03$ ), and presented higher ACQ mean scores (worse control) in comparison to respondents but did not differ in body mass index, treatment, number of other chronic conditions, SABA canisters prescribed last year, and frequency of SABA used in the previous 4 weeks.

\section{5-Level EuroQoL-5 Dimension Version Distribution}

Figure 1 shows the percentages of responses to each EQ-5D-5L dimension. Most subjects reported "no problems" in mobility $(81.0 \%, 226 / 279)$ and self-care $(98.2 \%, 274 / 279)$ dimensions, while only around half of the subjects endorsed this category in pain or discomfort $(45.5 \%, 127 / 279)$ and anxiety or depression $(48.0 \%, 134 / 279)$ dimensions. The "extreme problems" category was endorsed by 1 subject for pain and 7 for anxiety or depression.

Table 2 shows the distribution characteristics of EQ-5D-5L indices. In our sample, the EQ-5D-5L index constructed with the English value set ranged from 0.16 to 1 and from -0.074 to 1 when constructed with the French $3 \mathrm{~L}-5 \mathrm{~L}$ crosswalk value set. The mean was 0.88 (SD 0.14) for the English index and 0.83 (SD 0.19) for the French one. The Kurtosis statistics of 5.62 and 3.26, with skewness of -2.06 and -1.63 , indicated that the asymmetry to the right part of the distribution and the tail extremity were greater in the index constructed with the English EQ-5D-5L value set. The floor effect was null, and the ceiling effect was $26.5 \%$ (74/279). Cronbach alpha coefficient was .69, achieving the recommended standard [36,37].

\section{5-level EuroQoL-5 Dimension Version Construct Validity}

Table 3 presents results on the construct validity of the EQ-5D-5L based on known groups. Both EQ-5D-5L indices showed statistically significant different means for all known groups evaluated, while EQ-VAS only showed statistically significant differences among groups defined by ACQ scores. The mean EQ-5D-5L index for asthmatic patients decreased significantly with an increase in the number of other chronic conditions from 0.91 to 0.82 with the English value set and from 0.86 to 0.75 with the French $3 \mathrm{~L}-5 \mathrm{~L}$ crosswalk. The effect size between patients with none and those with $\geq 2$ other chronic conditions were 0.62 and 0.60 (moderate) with EQ-5D-5L indices. In addition, effect sizes were moderate between extreme groups defined by SABA canisters prescribed in the previous year (0.58 and 0.46$)$, and by the SABA frequency during the last 4 weeks (both 0.5). Finally, among groups defined by ACQ scores, the effect size between well-controlled and intermediately controlled asthma was moderate $(0.44$ and 0.47$)$ and large between well- and not well-controlled asthma (1.06 and 1.04). 
Table 1. The characteristics of included and excluded subjects.

\begin{tabular}{|c|c|c|c|}
\hline Characteristics & Included patients $(\mathrm{n}=279)$ & Excluded patients $(\mathrm{n}=302)$ & $P$ value \\
\hline Age (years), mean (SD) & $31.0(6.7)$ & $29.8(6.7)$ & .03 \\
\hline$<25, \mathrm{n}(\%)$ & $62(22.2)$ & $85(28.1)$ & .10 \\
\hline $25-34, \mathrm{n}(\%)$ & $119(42.7)$ & $133(44.0)$ & \\
\hline$\geq 35, \mathrm{n}(\%)$ & $98(35.1)$ & $84(27.8)$ & \\
\hline Gender, n (\%) & & & .47 \\
\hline Male & $110(39.4)$ & $128(42.4)$ & \\
\hline Female & $169(60.6)$ & $174(57.6)$ & \\
\hline Country & & & .01 \\
\hline France, n (\%) & $222(79.6)$ & $264(87.7)$ & \\
\hline United Kingdom, n (\%) & $57(20.4)$ & $37(12.3)$ & \\
\hline Missing (n) & 0 & 1 & \\
\hline Body mass index $\left(\mathrm{kg} / \mathrm{m}^{2}\right)$, mean (SD) & $25.2(6.2)$ & $25.4(5.8)$ & .79 \\
\hline Missing (n) & 127 & 107 & \\
\hline Treatment with, n (\%) & & & .18 \\
\hline $\mathrm{LABA}^{\mathrm{a}}$ & $11(3.9)$ & $9(3.0)$ & \\
\hline $\mathrm{ICs}^{\mathrm{b}}$ & $71(25.4)$ & $60(19.9)$ & \\
\hline LABA+ICs in separate inhalers & $37(13.3)$ & $33(10.9)$ & \\
\hline Fixed LABA and ICs combination & $160(57.3)$ & $200(66.2)$ & \\
\hline Other chronic conditions & & & .51 \\
\hline 0 conditions, $\mathrm{n}(\%)$ & $66(41.5)$ & $80(39.2)$ & \\
\hline 1 condition, $\mathrm{n}(\%)$ & $62(39.0)$ & $91(44.6)$ & \\
\hline$\geq 2$ conditions, $\mathrm{n}(\%)$ & $31(19.5)$ & $33(16.2)$ & \\
\hline Missing (n) & 120 & 98 & \\
\hline Number of $\mathrm{SABA}^{\mathrm{c}}$ canisters prescribed (last year) & & & .75 \\
\hline 0 canisters, $\mathrm{n}(\%)$ & $119(53.6)$ & $133(50.2)$ & \\
\hline $1-4$ canisters, $\mathrm{n}(\%)$ & $78(35.1)$ & $100(37.7)$ & \\
\hline$\geq 5$ canisters, $n(\%)$ & $25(11.3)$ & $32(12.1)$ & \\
\hline Missing (n) & 57 & $-\mathrm{d}$ & \\
\hline Frequency of SABA use reported by patient (last 4 weeks) & & & .63 \\
\hline Less than once a week, $\mathrm{n}(\%)$ & $166(61.9)$ & $171(65.5)$ & \\
\hline Once or twice every week, $\mathrm{n}(\%)$ & $71(26.5)$ & $60(23.0)$ & \\
\hline Almost every day or every day, $\mathrm{n}(\%)$ & $31(11.6)$ & $30(11.5)$ & \\
\hline Missing (n) & 11 & 41 & \\
\hline Asthma Control Questionnaire, mean (SD) & $1.01(0.92)$ & $1.35(1.01)$ & $<.001$ \\
\hline Well-controlled $(<0.75), \mathrm{n}(\%)$ & $119(44.6)$ & $89(34.1)$ & $<.001$ \\
\hline Intermediate $(0.75-1.5), \mathrm{n}(\%)$ & $82(30.7)$ & $63(24.1)$ & \\
\hline Not well-controlled (>1.5), n (\%) & $66(24.7)$ & $109(41.8)$ & \\
\hline Missing (n) & 12 & 41 & \\
\hline Highest education & & & Not calculated \\
\hline Secondary school or less, $\mathrm{n}(\%)$ & $13(4.7)$ & - & \\
\hline Sixth form or college, $\mathrm{n}(\%)$ & $41(14.9)$ & - & \\
\hline
\end{tabular}




\begin{tabular}{|c|c|c|c|}
\hline Characteristics & Included patients $(n=279)$ & Excluded patients $(\mathrm{n}=302)$ & $P$ value \\
\hline Bachelor degree, $\mathrm{n}(\%)$ & $184(66.9)$ & - & \\
\hline Postgraduate, n (\%) & $37(13.5)$ & - & \\
\hline Missing (n) & 4 & - & \\
\hline Work status & & & Not calculated \\
\hline Employed at usual job, n (\%) & $201(72.6)$ & - & \\
\hline On light duty or restricted work, $\mathrm{n}(\%)$ & $1(0.4)$ & - & \\
\hline Paid leave or sick leave, $\mathrm{n}(\%)$ & $4(1.4)$ & - & \\
\hline Unemployed because of other reason, $\mathrm{n}(\%)$ & $23(8.3)$ & - & \\
\hline Student (school, college, university), n (\%) & $35(12.6)$ & - & \\
\hline Keeping house or homemaker, n (\%) & $7(2.5)$ & - & \\
\hline Retired, n (\%) & $0(0.0)$ & - & \\
\hline On disability, n (\%) & $6(2.2)$ & - & \\
\hline Missing (n) & 2 & - & \\
\hline
\end{tabular}

${ }^{\mathrm{a}} \mathrm{LABA}$ : long-acting beta-agonist.

$\mathrm{b}$ IC: inhaled corticosteroid.

${ }^{\mathrm{c}} \mathrm{SABA}$ : short-acting beta-agonist.

${ }^{\mathrm{d}}$ Indicates missing data.

Figure 1. The percentage of patients' responses to each dimension.

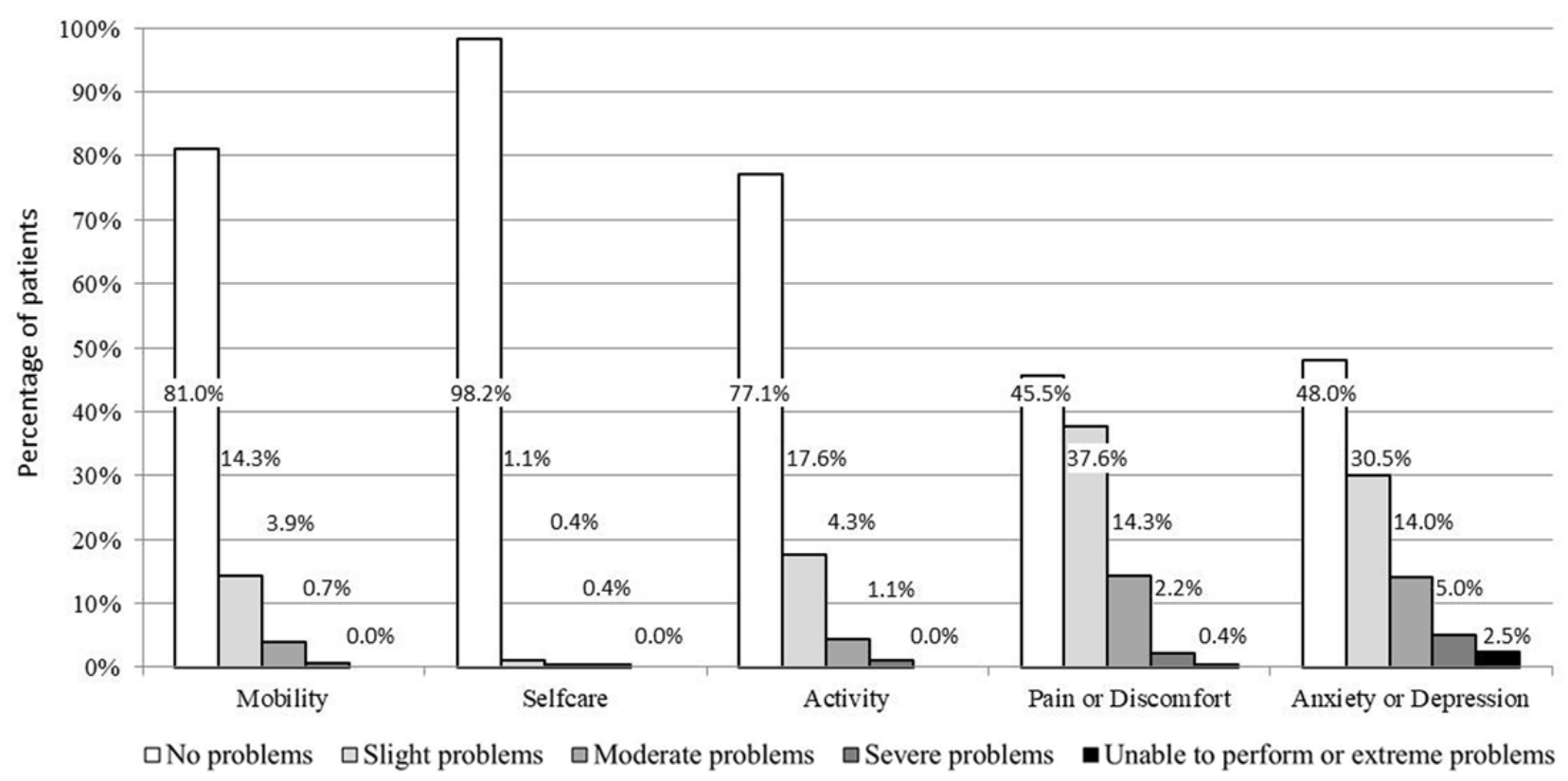


Table 2. The distribution of 5-level EuroQoL-5 dimension version indices ( $\mathrm{n}=279)$. Cronbach alpha coefficient was .69.

\begin{tabular}{lll}
\hline Statistics & EQ-5D-5L ${ }^{\mathrm{a}}$ (English value set) & EQ-5D-5L (French 3L-5L crosswalk value set) \\
\hline Theoretical range & -0.28097 to 1 & -0.530 to 1 \\
Observed range & 0.160 to 1 & -0.074 to 1 \\
Mean (SD) & $0.88(0.14)$ & $0.83(0.19)$ \\
Median (interquartile range) & $0.92(0.84$ to 1.00$)$ & $0.91(0.71$ to 1.00$)$ \\
Kurtosis (SE) & $5.62(0.29)$ & $3.26(0.29)$ \\
Skewness (SE) & $-2.06(0.15)$ & $-1.63(0.15)$ \\
Floor effect $(\%)$ & 0 & 0 \\
Ceiling effect $(\%)$ & 26.5 & 26.5 \\
\hline
\end{tabular}

${ }^{a}$ EQ-5D-5L: EuroQol-5 Dimensions-5 Levels.

Table 3. The construct validity of 5-level EuroQoL-5 dimension version.

\begin{tabular}{|c|c|c|c|c|c|c|}
\hline \multirow[t]{2}{*}{ Constructs } & \multicolumn{2}{|c|}{$\begin{array}{l}\text { EQ-5D-5L }{ }^{\mathrm{a}} \text { index (English value } \\
\text { set) }\end{array}$} & \multicolumn{2}{|c|}{$\begin{array}{l}\text { EQ-5D-5L index (French 3L-5L } \\
\text { crosswalk) }\end{array}$} & \multicolumn{2}{|c|}{ EuroQol visual analog scale } \\
\hline & Mean (SD) & Effect size $(95 \% \mathrm{CI})$ & Mean (SD) & Effect size $(95 \% \mathrm{CI})$ & Mean (SD) & Effect size $(95 \% \mathrm{CI})$ \\
\hline \multicolumn{7}{|l|}{ Other chronic conditions } \\
\hline 0 chronic conditions & $0.91(0.11)$ & Reference & $0.86(0.14)$ & Reference & $78.91(14.85)$ & Reference \\
\hline 1 chronic condition & $0.89(0.10)$ & $0.14(-0.21$ to 0.48$)$ & $0.85(0.15)$ & $0.05(-0.26$ to 0.36$)$ & $79.08(13.23)$ & $0.06(-0.25$ to 0.37$)$ \\
\hline$\geq 2$ chronic conditions & $0.82(0.13)$ & $0.62(0.18$ to 1.06$)$ & $0.75(0.20)$ & $0.60(0.18$ to 1.02$)$ & $72.94(17.22)$ & $0.37(-0.04$ to 0.79$)$ \\
\hline$P$ value & $.002^{\mathrm{b}, \mathrm{c}}$ & $-^{\mathrm{d}}$ & $.003^{\mathrm{b}, \mathrm{c}}$ & - & .12 & - \\
\hline \multicolumn{7}{|c|}{ Number of $\mathrm{SABA}^{\mathrm{e}}$ canisters prescribed (last year) } \\
\hline 0 canisters & $0.89(0.11)$ & Reference & $0.85(0.15)$ & Reference & $78.84(12.90)$ & Reference \\
\hline $1-4$ canisters & $0.87(0.14)$ & $0.11(-0.18$ to 0.39$)$ & $0.82(0.19)$ & $0.19(-0.07$ to 0.45$)$ & $76.64(17.93)$ & $0.21(-0.06$ to 0.47$)$ \\
\hline 5 or more canisters & $0.81(0.17)$ & $0.58(0.14$ to 1.01$)$ & $0.76(0.22)$ & $0.46(0.05$ to 0.86$)$ & $72.00(24.52)$ & $0.47(0.07$ to 0.88$)$ \\
\hline$P$ value & $.02^{\mathrm{b}}$ & - & $.03^{\mathrm{b}}$ & - & .15 & - \\
\hline \multicolumn{7}{|c|}{ Frequency of SABA use reported by patient (last 4 weeks) } \\
\hline Less than once a week & $0.82(0.19)$ & Reference & $0.74(0.23)$ & Reference & $71.45(19.85)$ & Reference \\
\hline Once or twice a week & $0.87(0.15)$ & $0.17(-0.11$ to 0.44$)$ & $0.81(0.21)$ & $0.29(0.03$ to 0.55$)$ & $78.08(12.92)$ & $0.07(-0.19$ to 0.32$)$ \\
\hline $\begin{array}{l}\text { Almost every day or every } \\
\text { day }\end{array}$ & $0.89(0.12)$ & $0.50(0.11$ to 0.89$)$ & $0.85(0.16)$ & $0.50(0.15$ to 0.84$)$ & $78.61(16.26)$ & $0.37(0.03$ to 0.71$)$ \\
\hline$P$ value & $.03^{\mathrm{b}}$ & - & $.01^{\mathrm{b}}$ & - & .07 & - \\
\hline \multicolumn{7}{|l|}{ Asthma Control Questionnaire } \\
\hline Well-controlled $(<0.75)$ & $0.93(0.10)$ & Reference & $0.91(0.13)$ & Reference & $81.65(13.80)$ & Reference \\
\hline Intermediate $(0.75-1.5)$ & $0.87(0.11)$ & $0.44(0.15$ to 0.72$)$ & $0.81(0.15)$ & $0.47(0.22$ to 0.73$)$ & $79.18(11.92)$ & $0.15(-0.11$ to 0.40$)$ \\
\hline Not well-controlled (>1.5) & $0.78(0.19)$ & $1.06(0.74$ to 1.38$)$ & $0.69(0.24)$ & $1.04(0.75$ to 1.32$)$ & $68.39(20.23)$ & $0.79(0.51$ to 1.08$)$ \\
\hline$P$ value & $<.001^{\mathrm{b}, \mathrm{c}, \mathrm{f}}$ & - & $<.001^{\mathrm{b}, \mathrm{c}, \mathrm{f}}$ & - & $<.001^{\mathrm{b}, \mathrm{c}}$ & - \\
\hline
\end{tabular}

${ }^{\mathrm{a}}$ EuroQol-5 Dimensions-5 Levels.

${ }^{\mathrm{b}}$ First category (reference) versus third category.

${ }^{\mathrm{c}}$ Second category versus third category.

${ }^{\mathrm{d}} P$ value not necessary as the $\mathrm{CI}$ was calculated.

${ }^{\text {e}} \mathrm{SABA}$ : short-acting beta-agonist.

${ }^{\mathrm{f}}$ First category (reference) versus second category. 


\section{Discussion}

\section{Principal Findings}

To the best of our knowledge, this is the first study evaluating metric properties of the new EQ-5D-5L in patients with asthma. In this study, this generic preference-based instrument showed adequate distribution and reliability, with $26.5 \%$ (74/279) of patients reporting the best possible health state (ceiling effect). In addition, it showed good construct validity, given its capacity of discriminating among groups differing in the number of chronic conditions and symptom control. The distribution of the EQ-5D-5L index was less skewed than the previously published one for the 3-level version owing to its lower ceiling effect $[15,17]$.

\section{Comparison of Web-Based Participation Rate With Prior Work}

In this study, 53.7\% (312/581) of participants completed the Web-based baseline survey, and almost all of these completed the EQ-5D-5L $(92.9 \%, 290 / 312)$. The internet era has led to implementing Web-based surveys to take advantage of the known benefits such as completeness [41,42], low expenses [43], and better data management. Nevertheless, there are still some barriers to Web-based self-completion, which could produce low response rates and selection bias. Although the reported participation rate varied a lot across Web-based surveys $[41,44,45]$, the $53.7 \%$ in this study is similar to those reported by other studies comparing different modes of data collection, such as $64.2 \%$ and $53.3 \%$ participation rates reported by Kongsved et al [41] and Hohwu et al [46] studies. Remarkably, both studies showed a slightly better response rate with the paper mode- $73.2 \%$ versus $64.2 \%$ [41] and $56.2 \%$ versus $53.3 \%$ [46]. In the ASTRO-LAB cohort, the high overall respondent burden (participants were asked to respond to yearly Web-based surveys, 4-monthly telephone interviews, and monthly short message service text messages) could have affected the response rate.

\section{Comparison With Prior Studies Evaluating the EuroQoL-5 Dimension Version in Patients With Asthma}

Despite being higher than the $15 \%$ [36] established for the ceiling effect, $26.5 \%$ (74/279) of patients with mild-to-moderate persistent asthma in the best possible health state in our sample was considerably lower than that reported in prior studies using the traditional EQ-5D-3L in paper-and-pencil administration $[15,17]$. A ceiling effect of $59 \%$ was described in Japanese patients with mild-to-severe asthma treated with ICs [15], and $50 \%$ in Canadian patients with mainly mild-to-moderate self-reported asthma [17]. In addition, our findings showed a lower proportion of patients with no problems in most dimensions than those reported by the 3-level version [15]-81.0\% (226/279) versus $90.7 \%$ in mobility, $77.1 \%$ $(215 / 279)$ versus $85.2 \%$ in activity, $45.5 \%$ (127/279) versus $74.1 \%$ in pain or discomfort, and $48.0 \%(134 / 279)$ versus $77.8 \%$ in anxiety or depression. The other 2 studies on the EQ-5D-3L in asthma [16,17] did not report percentage distributions for each dimension. This lower endorsement of the top response option when compared with results from previous studies with the EQ-5D-3L suggests that the "no problems" category (level 1 out of 3 ) is partially redistributed to the following intermediate category, "slight" problems (level 2 out of 5), in the new 5-level version. However, head-to-head studies are needed to ensure that the new 5L version's better properties we have observed, compared with results from previous EQ-5D-3L studies [15,17], are not explained by differences in patients' characteristics or design issues.

Studies that directly elicit preferences from representative general population samples to derive value sets for the new EQ-5D-5L, using a harmonized protocol, have already been published for several countries [30,47-51], but they are not yet developed in many others, including France. The EuroQol Group developed the $3 \mathrm{~L}-5 \mathrm{~L}$ crosswalk value sets as a temporary solution to estimate the EQ-5D-5L in such a situation [29]. The difference between both indices in the negative extreme of the theoretical range $(-0.28$ and -0.53$)$ is explained by the method used for the elicitation of the societal preference values to derive the value set: time trade-off in the French general population for the $3 \mathrm{~L}$ version [52], and the composite method of time trade-off with discrete choice experiments in the UK general population for the new $5 \mathrm{~L}$ version $[23,30]$. Our findings show that the mean EQ-5D-5L indices obtained with both value sets are quite similar $(0.88$ and 0.83$)$, supporting that the $3 \mathrm{~L}-5 \mathrm{~L}$ crosswalk is a good interim solution to calculate the EQ-5D-5L index, until definitive EQ-5D-5L value sets are available.

The EQ-5D-5L index could discriminate among different known groups in the hypothesized direction. In all the variables evaluated, differences between extreme groups ranged from 0.07 to 0.2 , therefore being equal to or higher than the minimal important difference, previously estimated as 0.07 [31]. The magnitude was moderate for differences among groups defined by the presence of other chronic conditions and SABA use or prescription and large for differences between patients with well- and not well-controlled asthma measured with the ACQ. McTaggart-Cowan et al [17], with the traditional EQ-5D-3L in patients with asthma, also showed differences between extreme groups $>0.07$, ranging from 0.07 to 0.18 . It was not possible to directly compare effect sizes with this study [17], as the variables to define known groups were different. Mc Taggart-Cowan et al reported a correlation of 0.37 for the ACQ with the EQ-5D-3L index [17], similar to the 0.43 found in our study with the EQ-5D-5L index. These findings indicate a good construct validity for the EQ-5D-5L index, which, in general, presented a greater discriminant capacity than the EQ-VAS among the known groups evaluated.

\section{Limitations and Strengths}

Some potential limitations of this study need to be considered. First, a direct comparison with the EQ-5D-3L was not possible. Although previous EQ-5D-3L studies in asthma patients [15-17] showed higher ceiling effects and lower discriminatory properties than ours with the EQ-5D-5L, differences among studies regarding patients' and design characteristics cannot be discarded. Second, as no asthma-specific HRQoL measure was included in this study, we were unable to compare the generic EQ-5D-5L with them. Studies evaluating the EQ-5D-3L in 
comparison to the Asthma Quality of Life Questionnaire [15-17] or the Newcastle Asthma Symptoms Questionnaire [16] showed that these disease-specific instruments were more sensitive to change. Further head-to-head studies comparing the EQ-5D-5L with disease-specific instruments are needed, mainly to compare responsiveness. Third, the usability of online versus other methods of survey administration could not be evaluated because all patients completed the Web-based EQ-5D-5L. Fourth, because the ASTRO-LAB project only included patients with mild-to-moderate persistent asthma, the generalizability of our results to those with intermittent or severe persistent asthma is uncertain. The generalizability is also uncertain to patients older than 40 years. Finally, it is important to note that $46.3 \%$ (269/581) of participants in the ASTRO-LAB project did not answer the Web-based survey. No differences in sociodemographic characteristics, treatment, and comorbidity were found between respondents and nonrespondents, and differences detected in asthma control were minor. However, there could be differences in other characteristics, which have not been measured such as personality or other psychological traits.

This study has several strengths that need to be highlighted. First, embedding this study in an observational cohort in routine care allowed us to select several appropriate known groups for evaluating the EQ-5D-5L's construct validity in patients with asthma. The relationship between comorbid chronic conditions and health is well established, and the associations of symptoms control [53] with the HRQoL have been extensively studied in this population. Furthermore, the ACQ, validated in 50 languages, is one of the most widely accepted instruments for measuring asthma control [54].

\section{Conclusions}

In summary, our results provide support to the construct validity of the EQ-5D-5L administered online to patients with asthma, based on its discriminant ability for distinguishing among health-related known groups, as well as its lower ceiling effect than previously reported for the traditional 3-level version $[15,17]$. The completion of the EQ-5D-5L by most of the Web-based survey respondents supports the feasibility of this administration form. As it was developed as a preference-based health status measure, the EQ-5D-5L index allows combining both length and quality of life, and calculates QALYs to measure health outcomes in economic evaluations. All these findings suggest that the new EQ-5D with 5 levels is a promising instrument to compare the efficiency of different programs or treatment strategies for asthma patients. Nevertheless, further studies are recommended to evaluate the responsiveness over time of the EQ-5D-5L among patients with asthma.

\section{Acknowledgments}

Financial support for this study was provided by the European Union Seventh Framework Programme FP7 (ASTROLAB project EC HEALTH-F5-2011-282593), Instituto de Salud Carlos III FEDER (PI12/00772), Fondo de Investigación Sanitaria, ISCIII (PI15/00449), Fondo de Investigación Sanitaria, ISCIII (PI16/00130), Fondo de Investigación Sanitaria, ISCIII (FI16/00071), ISCIII (Río Hortega, CM15/00167), and DIUE of Generalitat de Catalunya (2017 SGR 452, 2014 SGR 748). The funding agreement ensures the authors' independence in designing the study, interpreting the data, and writing and publishing the report. The authors would like to acknowledge Aurea Martin for her help in the English editing and proofreading process, and in finalizing this manuscript.

Members of the ASTRO-LAB group are: Sandrine Herbage, Manon Belhassen, Marine Ginoux (LBBE, University Claude Bernard Lyon 1, France); Stéphane Schück, Nathalie Texier, Sandy Leproust, Hélène Le Cloarec (Kappa Santé, France); Richard Hubbard (University of Nottingham, England); Alison Bourke, Mary Thompson, Delphine Vial, David Ansell (Cegedim Strategic Data, England); Javier Olaiz, Ana Valcarcel Orti (Lyon Ingénierie Projet, France); and authors MdB, ALD, EVG, LL, MF, OG, and $\mathrm{GH}$.

\section{Authors' Contributions}

GH contributed to the conception and design of the paper, conceptualized and oversaw analyses, contributed to the interpretation of data, and wrote the paper. AP contributed to the analysis and gave statistical support. ALD, OG, MMP, JA, EVG, LL, MdB, and KM oversaw all aspects and reviewed the paper for important intellectual content. VSS revised the draft versions of the manuscript. MF oversaw all aspects, contributed to the conception and design of the paper, contributed to the statistical analyses, carried out the interpretation of data, and contributed to the writing of the paper.

\section{Conflicts of Interest}

None declared.

\section{References}

1. Carranza RJR, Edwards L, Lincourt W, Dorinsky P, ZuWallack RL. The relationship between health-related quality of life, lung function and daily symptoms in patients with persistent asthma. Respir Med 2004 Dec;98(12):1157-1165. [Medline: 15588035]

2. McKenna SP. Measuring patient-reported outcomes: moving beyond misplaced common sense to hard science. BMC Med 2011 Jul 14;9:86 [FREE Full text] [doi: 10.1186/1741-7015-9-86] [Medline: 21756344] 
3. Global Initiative for Asthma. 2018. Global Strategy for Asthma Management and Prevention URL: https://ginasthma.org [accessed 2018-09-26] [WebCite Cache ID 72j3Zhq3B]

4. Stucky BD, Sherbourne CD, Edelen MO, Eberhart NK. Understanding asthma-specific quality of life: moving beyond asthma symptoms and severity. Eur Respir J 2015 Sep;46(3):680-687 [FREE Full text] [doi: 10.1183/09031936.00225014] [Medline: 25882804]

5. Chen H, Gould MK, Blanc PD, Miller DP, Kamath TV, Lee JH, TENOR Study Group. Asthma control, severity, and quality of life: quantifying the effect of uncontrolled disease. J Allergy Clin Immunol 2007 Aug;120(2):396-402. [doi: 10.1016/j.jaci.2007.04.040] [Medline: 17561244]

6. Schatz M, Mosen DM, Kosinski M, Vollmer WM, Magid DJ, O'Connor E, et al. The relationship between asthma-specific quality of life and asthma control. J Asthma 2007 Jun;44(5):391-395. [doi: 10.1080/02770900701364296] [Medline: $\underline{17613636]}$

7. Hunger M, Sabariego C, Stollenwerk B, Cieza A, Leidl R. Validity, reliability and responsiveness of the EQ-5D in German stroke patients undergoing rehabilitation. Qual Life Res 2012 Sep;21(7):1205-1216. [doi: 10.1007/s11136-011-0024-3] [Medline: 21971874]

8. König H, Born A, Günther O, Matschinger H, Heinrich S, Riedel-Heller SG, et al. Validity and responsiveness of the EQ-5D in assessing and valuing health status in patients with anxiety disorders. Health Qual Life Outcomes 2010 May 05;8:47 [FREE Full text] [doi: 10.1186/1477-7525-8-47] [Medline: 20444251]

9. Hung M, Lu W, Chen S, Hou W, Hsieh C, Wang J. Validation of the EQ-5D in Patients with Traumatic Limb Injury. J Occup Rehabil 2015 Jun;25(2):387-393. [doi: 10.1007/s10926-014-9547-0] [Medline: 25261389]

10. EQ-5D. EQ-5D User Guides URL: https://euroqol.org/publications/user-guides [accessed 2018-09-26] [WebCite Cache ID 72j34C3U7]

11. Gibbons E, Fitzpatrick R. Patient Reported Outcome Measurement Group, Oxford. The University of Oxford: Oxford, UK; 2009. A structured review of patient-reported outcome measures (PROMs) for asthma URL: http://phi.uhce.ox.ac.uk/pdf/ PROMs Oxford Asthma 17092010 [accessed 2018-09-26] [WebCite Cache ID 72j5h8ddn]

12. Räsänen P, Roine E, Sintonen H, Semberg-Konttinen V, Ryynänen O, Roine R. Use of quality-adjusted life years for the estimation of effectiveness of health care: A systematic literature review. Int J Technol Assess Health Care 2006;22(2):235-241. [doi: 10.1017/S0266462306051051] [Medline: 16571199]

13. Richardson J, McKie J, Bariola E. Multi attribute utility instruments and their use. In: Culyer AJ, editor. Encyclopedia of health economics. San Diego: Elsevier Science; 2014:341-357.

14. Fauteux V, Poder T. État des lieux sur les méthodes d'élicitation du QALY Overview of QALY elicitation methods. Int J Health Pref Research 2017;1:001-014. [doi: 10.21965/IJHPR.2017.001]

15. Oga T, Nishimura K, Tsukino M, Sato S, Hajiro T, Mishima M. A comparison of the responsiveness of different generic health status measures in patients with asthma. Qual Life Res 2003 Aug;12(5):555-563. [Medline: 13677500]

16. Garratt AM, Hutchinson A, Russell I. Patient-assessed measures of health outcome in asthma: a comparison of four approaches. Respir Med 2000 Jun;94(6):597-606 [FREE Full text] [doi: 10.1053/rmed.2000.0787] [Medline: 10921766]

17. McTaggart-Cowan HM, Marra CA, Yang Y, Brazier JE, Kopec JA, FitzGerald JM, et al. The validity of generic and condition-specific preference-based instruments: the ability to discriminate asthma control status. Qual Life Res 2008 Apr;17(3):453-462. [doi: 10.1007/s11136-008-9309-6] [Medline: 18274882]

18. Brazier J, Roberts J, Tsuchiya A, Busschbach J. A comparison of the EQ-5D and SF-6D across seven patient groups. Health Econ 2004 Sep;13(9):873-884. [doi: 10.1002/hec.866] [Medline: 15362179]

19. Janssen MF, Lubetkin EI, Sekhobo JP, Pickard AS. The use of the EQ-5D preference-based health status measure in adults with Type 2 diabetes mellitus. Diabet Med 2011 Apr;28(4):395-413. [doi: 10.1111/j.1464-5491.2010.03136.x] [Medline: 21392061]

20. van Stel HF, Buskens E. Comparison of the SF-6D and the EQ-5D in patients with coronary heart disease. Health Qual Life Outcomes 2006 Mar 25;4:20 [FREE Full text] [doi: 10.1186/1477-7525-4-20] [Medline: 16563170]

21. Feeny D, Furlong W, Torrance GW, Goldsmith CH, Zhu Z, DePauw S, et al. Multiattribute and single-attribute utility functions for the health utilities index mark 3 system. Med Care 2002 Feb;40(2):113-128. [Medline: 11802084]

22. Brazier J, Roberts J, Deverill M. The estimation of a preference-based measure of health from the SF-36. J Health Econ 2002 Mar;21(2):271-292. [Medline: 11939242]

23. Oppe M, Devlin NJ, van Hout B, Krabbe PFM, De Leon MC. A program of methodological research to arrive at the new international EQ-5D-5L valuation protocol. Value Health 2014 Jun;17(4):445-453 [FREE Full text] [doi:

10.1016/j.jval.2014.04.002] [Medline: 24969006]

24. Pickard AS, De Leon MC, Kohlmann T, Cella D, Rosenbloom S. Psychometric comparison of the standard EQ-5D to a 5 level version in cancer patients. Med Care 2007 Mar;45(3):259-263. [doi: 10.1097/01.mlr.0000254515.63841.81] [Medline: 17304084]

25. Kim SH, Kim HJ, Lee S, Jo M. Comparing the psychometric properties of the EQ-5D-3L and EQ-5D-5L in cancer patients in Korea. Qual Life Res 2012 Aug;21(6):1065-1073. [doi: 10.1007/s11136-011-0018-1] [Medline: 21947656]

26. Jia YX, Cui FQ, Li L, Zhang DL, Zhang GM, Wang FZ, et al. Comparison between the EQ-5D-5L and the EQ-5D-3L in patients with hepatitis B. Qual Life Res 2014 Oct;23(8):2355-2363. [doi: 10.1007/s11136-014-0670-3] [Medline: 24627090] 
27. Van Ganse E, Texier N, Dima AL, Laforest L, Ferrer M, Hernandez G, ASTRO-LAB group. Assessment of the safety of long-acting $\beta 2$-agonists in routine asthma care: the ASTRO-LAB protocol. NPJ Prim Care Respir Med 2015 Jun 18;25:15040 [FREE Full text] [doi: 10.1038/npjpcrm.2015.40] [Medline: 26086323]

28. Schatz M, Zeiger RS, Yang ST, Chen W, Crawford WW, Sajjan SG, et al. Relationship of asthma control to asthma exacerbations using surrogate markers within a managed care database. Am J Manag Care 2010 May;16(5):327-333 [FREE Full text] [Medline: 20469953]

29. van Hout B, Janssen MF, Feng Y, Kohlmann T, Busschbach J, Golicki D, et al. Interim scoring for the EQ-5D-5L: mapping the EQ-5D-5L to EQ-5D-3L value sets. Value Health 2012;15(5):708-715 [FREE Full text] [doi: 10.1016/j.jval.2012.02.008] [Medline: 22867780]

30. Devlin NJ, Shah KK, Feng Y, Mulhern B, van Hout B. Valuing health-related quality of life: An EQ-5D-5L value set for England. Health Econ 2018 Jan;27(1):7-22. [doi: 10.1002/hec.3564] [Medline: 28833869]

31. McClure NS, Sayah FA, Xie F, Luo N, Johnson JA. Instrument-Defined Estimates of the Minimally Important Difference for EQ-5D-5L Index Scores. Value Health 2017 Apr;20(4):644-650. [doi: 10.1016/j.jval.2016.11.015] [Medline: 28408007]

32. Reddel HK, Taylor DR, Bateman ED, Boulet L, Boushey HA, Busse WW, American Thoracic Society/European Respiratory Society Task Force on Asthma Control and Exacerbations. An official American Thoracic Society/European Respiratory Society statement: asthma control and exacerbations: standardizing endpoints for clinical asthma trials and clinical practice. Am J Respir Crit Care Med 2009 Jul 1;180(1):59-99. [doi: 10.1164/rccm.200801-060ST] [Medline: 19535666]

33. Taylor DR, Bateman ED, Boulet L, Boushey HA, Busse WW, Casale TB, et al. A new perspective on concepts of asthma severity and control. Eur Respir J 2008 Sep;32(3):545-554 [FREE Full text] [doi: 10.1183/09031936.00155307] [Medline: $\underline{18757695]}$

34. Juniper EF, Svensson K, Mörk A, Ståhl E. Measurement properties and interpretation of three shortened versions of the asthma control questionnaire. Respir Med 2005 May;99(5):553-558 [FREE Full text] [doi: 10.1016/j.rmed.2004.10.008] [Medline: 15823451$]$

35. Juniper EF, Bousquet J, Abetz L, Bateman ED. Identifying 'well-controlled' and 'not well-controlled' asthma using the Asthma Control Questionnaire. Respir Med 2006 Apr;100(4):616-621 [FREE Full text] [doi: 10.1016/j.rmed.2005.08.012] [Medline: $\underline{16226443}$ ]

36. Terwee CB, Bot SD, de Boer MR, van der Windt DA, Knol DL, Dekker J, et al. Quality criteria were proposed for measurement properties of health status questionnaires. J Clin Epidemiol 2007 Jan;60(1):34-42. [doi:

10.1016/j.jclinepi.2006.03.012] [Medline: 17161752]

37. Aaronson N, Alonso J, Burnam A, Lohr KN, Patrick DL, Perrin E, et al. Assessing health status and quality-of-life instruments: attributes and review criteria. Qual Life Res 2002 May;11(3):193-205. [Medline: 12074258]

38. Chen W, Lynd LD, FitzGerald JM, Marra CA, Rousseau R, Sadatsafavi M. The added effect of comorbidity on health-related quality of life in patients with asthma. Qual Life Res 2015 Oct;24(10):2507-2517. [doi: 10.1007/s11136-015-0995-6] [Medline: 26038225]

39. Moy ML, Fuhlbrigge AL, Blumenschein K, Chapman RH, Zillich AJ, Kuntz KM, et al. Association between preference-based health-related quality of life and asthma severity. Ann Allergy Asthma Immunol 2004 Mar;92(3):329-334. [doi: 10.1016/S1081-1206(10)61570-0] [Medline: 15049396]

40. Cohen J. Statistical Power Analysis for the Behavioral Sciences. New York: Taylor \& Francis, Inc; 1988.

41. Kongsved SM, Basnov M, Holm-Christensen K, Hjollund NH. Response rate and completeness of questionnaires: a randomized study of Internet versus paper-and-pencil versions. J Med Internet Res 2007;9(3):e25 [FREE Full text] [doi: 10.2196/jmir.9.3.e25] [Medline: 17942387]

42. Ritter P, Lorig K, Laurent D, Matthews K. Internet versus mailed questionnaires: a randomized comparison. J Med Internet Res 2004 Sep 15;6(3):e29 [FREE Full text] [doi: 10.2196/jmir.6.3.e29] [Medline: 15471755]

43. Scott A, Jeon S, Joyce CM, Humphreys JS, Kalb G, Witt J, et al. A randomised trial and economic evaluation of the effect of response mode on response rate, response bias, and item non-response in a survey of doctors. BMC Med Res Methodol 2011;11:126 [FREE Full text] [doi: 10.1186/1471-2288-11-126] [Medline: 21888678]

44. Fouladi RT, McCarthy CJ, Moller NP. Paper-and-pencil or online? Evaluating mode effects on measures of emotional functioning and attachment. Assessment 2002 Jun;9(2):204-215. [doi: 10.1177/10791102009002011] [Medline: 12066835]

45. Ekman A, Dickman PW, Klint A, Weiderpass E, Litton J. Feasibility of using web-based questionnaires in large population-based epidemiological studies. Eur J Epidemiol 2006;21(2):103-111. [doi: 10.1007/s10654-005-6030-4] [Medline: 16518678]

46. Hohwü L, Lyshol H, Gissler M, Jonsson SH, Petzold M, Obel C. Web-based versus traditional paper questionnaires: a mixed-mode survey with a Nordic perspective. J Med Internet Res 2013;15(8):e173 [FREE Full text] [doi: $\underline{10.2196 / j \mathrm{mir} .2595]}$ [Medline: 23978658]

47. Augustovski F, Rey-Ares L, Irazola V, Garay OU, Gianneo O, Fernández G, et al. An EQ-5D-5L value set based on Uruguayan population preferences. Qual Life Res 2016 Feb;25(2):323-333. [doi: 10.1007/s11136-015-1086-4] [Medline: 26242249] 
48. Xie F, Pullenayegum E, Gaebel K, Bansback N, Bryan S, Ohinmaa A, et al. A Time Trade-off-derived Value Set of the EQ-5D-5L for Canada. Med Care 2016 Jan;54(1):98-105 [FREE Full text] [doi: 10.1097/MLR.0000000000000447] [Medline: 26492214]

49. Kim S, Ahn J, Ock M, Shin S, Park J, Luo N, et al. The EQ-5D-5L valuation study in Korea. Qual Life Res 2016 Dec;25(7):1845-1852. [doi: 10.1007/s11136-015-1205-2] [Medline: 26961008]

50. Xie F, Pullenayegum E, Gaebel K, Oppe M, Krabbe PFM. Eliciting preferences to the EQ-5D-5L health states: discrete choice experiment or multiprofile case of best-worst scaling? Eur J Health Econ 2013 Apr 4;15(3):281-288. [doi: 10.1007/s10198-013-0474-3]

51. Versteegh MM, Vermeulen KM, Evers SMAA, de Wit GA, Prenger R, Stolk EA. Dutch Tariff for the Five-Level Version of EQ-5D. Value Health 2016 Dec;19(4):343-352 [FREE Full text] [doi: 10.1016/j.jval.2016.01.003] [Medline: 27325326]

52. Chevalier J, de Pouvourville G. Valuing EQ-5D using time trade-off in France. Eur J Health Econ 2013 Feb;14(1):57-66. [doi: 10.1007/s10198-011-0351-x] [Medline: 21935715]

53. King MT, Kenny PM, Marks GB. Measures of asthma control and quality of life: longitudinal data provide practical insights into their relative usefulness in different research contexts. Qual Life Res 2009 Apr;18(3):301-312. [doi: 10.1007/s11136-009-9448-4] [Medline: 19225906]

54. Worth A, Hammersley V, Knibb R, Flokstra-de-Blok B, DunnGalvin A, Walker S, et al. Patient-reported outcome measures for asthma: a systematic review. NPJ Prim Care Respir Med 2014 Jun 26;24:14020 [FREE Full text] [doi: 10.1038/npjpcrm.2014.20] [Medline: 24964767]

\author{
Abbreviations \\ ACQ: Asthma Control Questionnaire \\ EQ-5D-5L: 5-level EuroQoL-5 dimension version \\ EQ-VAS: EuroQol-visual analog scale \\ HRQoL: Health-Related Quality of Life \\ IC: inhaled corticosteroid \\ LABA: long-acting beta-agonists \\ SABA: short-acting beta-agonists
}

Edited by G Eysenbach; submitted 14.03.18; peer-reviewed by T Poder, D Williams, M Duplaga; comments to author 03.08.18;
revised version received 27.09.18; accepted 03.10.18; published 23.01.19
Please cite as:
Hernandez G, Garin O, Dima AL, Pont A, Marti Pastor M, Alonso J, Van Ganse E, Laforest L, de Bruin M, Mayoral K, Serra-Sutton
V, Ferrer M, ASTRO-LAB Group
EuroQol (EQ-5D-5L) Validity in Assessing the Quality of Life in Adults With Asthma: Cross-Sectional Study
J Med Internet Res 2019;21(1):e10178
URL: $\underline{\text { http://www.jmir.org/2019/1/e10178/ }}$
doi: $\underline{10.2196 / 10178}$
PMID: $\underline{30672744}$

(C) Gimena Hernandez, Olatz Garin, Alexandra L Dima, Angels Pont, Marc Martí Pastor, Jordi Alonso, Eric Van Ganse, Laurent Laforest, Marijn de Bruin, Karina Mayoral, Vicky Serra-Sutton, Montse Ferrer, ASTRO-LAB Group. Originally published in the Journal of Medical Internet Research (http://www.jmir.org), 23.01.2019. This is an open-access article distributed under the terms of the Creative Commons Attribution License (https://creativecommons.org/licenses/by/4.0/), which permits unrestricted use, distribution, and reproduction in any medium, provided the original work, first published in the Journal of Medical Internet Research, is properly cited. The complete bibliographic information, a link to the original publication on http://www.jmir.org/, as well as this copyright and license information must be included. 